\title{
The association of therapeutic versus recreational marijuana use and antiretroviral adherence among adults living with HIV in Florida
}

This article was published in the following Dove Press journal:

Patient Preference and Adherence

\author{
Zachary L Mannes' \\ Larry E Burrell II' \\ Erin G Ferguson' \\ Zhi Zhou ${ }^{2,3}$ \\ Huiyin $\mathrm{Lu}^{4,5}$ \\ Charurut Somboonwit ${ }^{6}$ \\ Robert L Cook ${ }^{2,3}$ \\ Nicole Ennis' \\ 'Department of Clinical and Health \\ Psychology, College of Public Health \\ and Health Professions, University \\ of Florida, Gainesville, FL, USA; \\ ${ }^{2}$ Department of Epidemiology, \\ College of Public Health and \\ Health Professions, ${ }^{3}$ Department of \\ Epidemiology, College of Medicine, \\ University of Florida, Gainesville, FL, \\ USA; ${ }^{4}$ Department of Biostatistics, \\ College of Public Health and \\ Health Professions, ${ }^{5}$ Department of \\ Biostatistics, College of Medicine, \\ University of Florida, Gainesville, \\ Florida, USA; ${ }^{6}$ Department of \\ Internal Medicine, Morsani College of \\ Medicine, University of South Florida, \\ Tampa, FL, USA
}

Correspondence: Nicole Ennis Department of Clinical and Health Psychology, College of Public Health and Health Professions, University of Florida, I 225 Center Drive, Room 3146, PO Box I00165, Gainesville, FL 32610-0I65, USA Tel +I 3522736145

Email nennis@phhp.ufl.edu
Purpose: Marijuana use is common among people living with HIV (PLWH), but its association with antiretroviral therapy (ART) adherence is unclear. This study examined the association between reason for marijuana use and ART adherence in a sample of adults living with HIV.

Patients and methods: Participants $(\mathrm{N}=703)$ recruited from seven community health centers in Florida completed a 45-minute questionnaire assessing demographics, symptoms of anxiety and depression, ART adherence, and substance use, including reasons for marijuana use. ART adherence was defined as the proportion of days in the last 30 days participants did not miss any medication and dichotomized as optimal ( $\geq 95 \%)$ and suboptimal $(<95 \%)$. Multivariate logistic regression analysis assessed the association between therapeutic marijuana use to manage HIV symptoms (ie, improve appetite/gain weight, induce sleep, relieve nausea/vomiting, relieve pain, relieve anxiety/depression/stress) versus recreational marijuana use and ART adherence.

Results: Approximately one third (33.2\%) of the participants reported using marijuana in the past 3 months. Of marijuana users, $21.8 \%$ reported using marijuana only for therapeutic purposes to manage HIV-associated medical symptoms, while $78.2 \%$ reported recreational use. After controlling for covariates, therapeutic use of marijuana was not associated with ART adherence $(\mathrm{AOR}=1.19,95 \% \mathrm{CI}=0.60-2.38, p=0.602)$ while recreational marijuana users showed significantly greater odds of suboptimal ART adherence compared to nonusers (AOR $=1.80$, 95\% CI $=1.18-2.72, p=0.005$ ).

Conclusion: Our results suggest differences in ART adherence between individuals who report recreational versus therapeutic marijuana use. Continued research examining the health implications of marijuana use among adults living with HIV is important as legalization of recreational and medical marijuana proliferates in the United States.

Keywords: HIV/AIDS, marijuana use, antiretroviral therapy, antiretroviral adherence

\section{Introduction}

Adherence to an antiretroviral therapy (ART) regimen has significantly improved HIV-related morbidity and mortality, making it perhaps the most salient behavior to optimize health among people living with HIV (PLWH). ${ }^{1-3}$ Optimal adherence is linked to viral suppression, improved immune functioning, and decreased disease transmission. ${ }^{2,4}$ Despite these benefits, suboptimal medication adherence is a problem that persists in HIV treatment. Factors such as demographic characteristics (eg, age, female sex, and African-American race), depression, and illicit drug use have all been associated with suboptimal adherence in HIV treatment. ${ }^{5-8}$ While psychoactive drug use has been associated with suboptimal adherence among PLWH, marijuana use may have potential medicinal benefits in this population. ${ }^{9-12}$ 
Marijuana use is prevalent among PLWH, with up to $60 \%$ of adults in this population reporting current use..$^{13-17}$ Although up to $75 \%$ of PLWH who use marijuana report recreational motives, several studies have also shown that many adults in this population report using marijuana to manage HIV-associated symptoms, such as pain, nausea, lack of appetite, insomnia, anxiety, and depression. ${ }^{9-12,18,19}$ D'Souza et al showed that the most prevalent rationales for marijuana use among PLWH were to relax or reduce stress $(86 \%)$, to increase appetite (58\%), and to reduce HIV symptoms such as nausea (38\%). ${ }^{19}$ Marijuana may be associated with improved HIV symptom management, as Woolridge et al noted that $27 \%$ of PLWH reported managing HIVassociated symptomatology with marijuana and that $80 \%$ of those participants endorsed improvements in nausea, pain, anxiety, and depression. ${ }^{12}$

Conversely, smoked marijuana is associated with deleterious effects on the cardiopulmonary system. ${ }^{20}$ In addition, marijuana use is associated with impairments in memory and attention. ${ }^{21}$ Research also suggests that marijuana use exacerbates HIV-associated neurocognitive deficits. ${ }^{22}$ Moreover, marijuana use is associated with the exacerbation of psychopathology, decreased engagement in social roles, and increased use of other illicit substances; all of which negatively affect treatment adherence. ${ }^{23}$

Studies examining marijuana use and ART adherence suggest mixed results. De Jong et al noted that marijuana use was not associated with adherence, although alcohol use and other illicit substances reduced the likelihood of achieving optimal ART adherence. ${ }^{5}$ Slawson et al drew similar findings, as at least daily use of marijuana was not associated with ART adherence. ${ }^{24}$ In contrast, other studies have found that marijuana use is associated with suboptimal medication adherence. ${ }^{8,19,25-28}$ To date, previous studies have exclusively examined the presence or absence of use as well as the frequency of marijuana use in relation to ART adherence, thereby negating potential important distinctions in motives (ie, recreational use versus use to manage HIV-associated medical symptoms) for marijuana use.

Florida is a salient locale to examine the association between motive for use and ART adherence, as the state currently has the third highest prevalence of PLWH in the United States and has experienced an increasing incidence of HIV since 2013. ${ }^{29}$ Due to the legalization of medical marijuana in Florida in 2017, physician prescribed medical marijuana was not assessed as data for this study was collected prior to legalization. Many consider medical marijuana to represent that which is prescribed or recommended by a physician, but PLWH often report using it to self-manage medical conditions, as it is one of the most common types of complementary and alternative medicine used by PLWH in Florida. ${ }^{30}$ We therefore sought to compare ART adherence among PLWH who used marijuana to self-manage specific symptoms or health conditions (therapeutic use), compared to those who used it recreationally.

Thus, the present study aimed to examine the association between therapeutic versus recreational marijuana use and ART adherence among adults living with HIV in Florida. We hypothesized that individuals reporting recreational marijuana use would be significantly more likely than nonmarijuana users and therapeutic users to exhibit suboptimal ART adherence.

\section{Patients and methods Participants and procedures}

The sample $(\mathrm{N}=703)$ included participants recruited from October 2014 to March 2017 from the Florida Cohort, an ongoing National Institute on Alcohol Abuse and Alcoholism (NIAAA)-funded study examining health outcomes among PLWH receiving care within Florida. Participants were recruited at multiple county health departments, community clinics, and settings throughout Florida (ie, Gainesville, Ft Lauderdale, Lake City, Miami, Orlando, Sanford, and Tampa). Persons with HIV were informed about the study by clinic or facility staff, or by brochures. All adults living with HIV were eligible to participate. After providing written informed consent, participants completed a self-administered 45-minute questionnaire on paper or via a secured laptop assessing information regarding demographics, symptoms of anxiety and depression, ART adherence, and substance use and misuse. Participants received $\$ 25.00$ for completing the study. The Institutional Review Boards of the University of Florida, Florida International University, and Florida Department of Health approved this study.

\section{Measures}

\section{ART adherence}

Participants answered the question, "In the last 30 days, how many days did you miss at least one dose of your HIV medication?"31 ART adherence was defined as the proportion of days in the last 30 days they did not miss any medication and dichotomized as optimal ( $\geq 95 \%$ ) and suboptimal $(<95 \%)$ adherence. Previous studies demonstrate that $\geq 95 \%$ ART adherence is strongly associated with HIV-1 RNA viral suppression and increased CD4+ count. . $4,32,33^{2}$ 


\section{Marijuana use}

Participants who endorsed marijuana use within the past 3 months answered questions pertaining to frequency (on average, how often have you used marijuana in the past 3 months?), frequency on days of use (in the past 3 months, on days when you used marijuana, how many times did you use on average?), and duration of at least weekly use (how many years have you used marijuana at least once per week?). Marijuana users reported their preferred route of administration (ROA; ie, joints, blunts, pipes, vaporizing devices, and ingestion/ edibles). Participants were dichotomized as yes or no based on whether or not they endorsed any use by those means.

Participants reporting using marijuana in the past 3 months were asked to report how often they used marijuana for several specific reasons. In line with Schauer et al classification of reasons for marijuana use developed in collaboration with the Centers for Disease Control and Prevention, we defined recreational marijuana users as those who endorsed use often or sometimes for the purpose of getting high or stoned, increasing libido/improving sexual performance, or fitting into social situations. ${ }^{34}$ Participants using to manage HIV-associated medical symptoms reported using marijuana often or sometimes for any of the following five reasons: improving appetite/gaining weight, inducing sleep, relieving nausea/vomiting, relieving pain, and relieving anxiety/depression/stress. Participants endorsing marijuana use for both recreational and therapeutic purposes were classified as recreational users. Participants reporting any marijuana use were thus classified into two groups based on their reasons of use: any recreational use and therapeutic users only.

\section{Other substance use}

Participants self-reported substance use in the last 12 months including alcohol, tobacco, and illicit drug use other than marijuana. Hazardous drinking was defined as consuming more than 14 drinks per week or $\geq 5$ drinks per occasion at least monthly in the past 12 months for males and $>7$ drinks per week or $\geq 4$ drinks per occasion at least monthly for females, which has been shown to place PLWH at increased risk for adverse health events. ${ }^{35,36}$ Tobacco use and any other illicit drug use within the past 12 months were dichotomized as yes or no, respectively.

\section{Depression}

The eight-item Patient Health Questionnaire (PHQ-8) was used to assess current depressive symptoms. A cutoff of $\geq 10$ has been previously established to define current depression. ${ }^{37}$ The PHQ- 8 has demonstrated high reliability and validity among PLWH. ${ }^{37,38}$ The eight items comprising the PHQ- 8 demonstrated good $(\alpha=0.88)$ internal consistency in this sample.

\section{Anxiety}

The 7-item Generalized Anxiety Disorder (GAD-7) Scale was utilized to assess current anxiety symptoms. Scores ranging from 0 to 9 were categorized as no/mild symptoms of anxiety and scores $\geq 10$ were categorized as moderate/ severe. The GAD-7 has shown good validity and adequate internal consistency $(\alpha=0.79-0.91)$ as a screener for generalized anxiety disorder in previous studies and demonstrated excellent $(\alpha=0.92)$ internal consistency in this sample. ${ }^{39,40}$

\section{Sociodemographics}

Age, race, sex, homelessness, level of education, and marital status were collected. Participants were categorized into four age groups: $18-34,35-44,45-54$, and $\geq 55$ years. Race/ ethnicity was categorized into Hispanic, White, Black, and others. Sex was based on participant's sex at birth (ie, male or female). Level of education was classified into three groups: less than high school, high school, and more than high school. Homelessness was defined as living in a homeless shelter, emergency shelter, car, street, or abandoned building in the last 12 months. Marital status was dichotomized as married or living with a long-term partner versus being single, divorced, widowed, or separated.

\section{Statistical analyses}

Participants were categorized into those reporting recreational use, therapeutic use to manage HIV-associated medical symptoms, or as nonusers. Bivariate analyses were conducted using chi-square tests to assess the differences in frequency, frequency on days of use, duration of at least weekly use, and ROA among the two marijuana use groups, as well as to assess differences in demographics, mental health variables, substance use, and ART adherence among the two marijuana use groups and nonusers. To further assess the association between the primary independent variable, reason for marijuana use, and the dichotomous ART adherence variable $(\geq 95 \%=$ coded as 1 , and $<95 \%=$ coded as 2), we utilized multivariate logistic regression analysis controlling for potential confounding variables associated with marijuana use in bivariate analysis $(p<0.05$; ie, homelessness, cigarette smoking, hazardous drinking, and other drug use), as well as demographic variables (ie, sex, age, and race) commonly associated with ART adherence. Multivariate analysis investigating the association between recreational versus therapeutic marijuana use and 
ART adherence utilized "nonusers" as the designated referent group. Crude and adjusted odds ratios (AORs) with 95\% CIs were presented. All statistical analyses were conducted using SPSS Version $24 .^{41}$

\section{Results}

\section{Sample characteristics}

The sample $(\mathrm{N}=703)$ had a mean age of 47.08 years ( $\mathrm{SD}=11.27$ ). The racial/ethnic breakdown was 53.7\% Black, $22.4 \%$ White, $20.4 \%$ Hispanic, and $3.5 \%$ others. The majority of participants (68.7\%) were males. Most (62.2\%) had a high school diploma or less, while $37.9 \%$ reported obtaining a degree beyond high school. The majority of participants $(81.0 \%)$ reported being unmarried. Mean years since HIV diagnosis was 11.52 (SD =7.61). Approximately one third $(32.0 \%)$ of the sample reported $<95 \%$ ART adherence.

\section{Recreational and therapeutic marijuana use}

Marijuana use in the past 3 months was reported by $33.2 \%$ of participants. Over one-fourth $(26.0 \%)$ of all participants reported using marijuana for recreational purposes, of which $88.5 \%$ reported using recreationally to get high or stoned. Regarding therapeutic use to manage HIV-associated symptoms, $26.5 \%$ of the sample reported use to relieve anxiety, depression, or stress; the most prevalent rationale reported among all therapeutic marijuana users. In addition, 22.3\% reported use to induce sleep, $22.2 \%$ reported pain relief, $21.3 \%$ reported use to improve appetite/gain weight, and $14.9 \%$ reported use to relieve nausea/vomiting. Most (70.3\%) marijuana users reported using for both recreational and therapeutic purposes, with only $7.7 \%$ reporting exclusive recreational use (Table 1$)$.

After categorization, 51 (7.2\%) of all participants reported only therapeutic use to manage HIV-associated medical symptoms, $183(26.0 \%)$ were recreational users, and $66.8 \%$ were nonusers. Of marijuana users, $21.8 \%$ were therapeutic users, while $78.2 \%$ were recreational users. Approximately one third $(33.3 \%)$ of all marijuana users were daily users, while an additional $23.9 \%$ reported using marijuana at least weekly. There were no significant differences in marijuana use frequency between therapeutic users and recreational users $\left(\chi^{2}=1.10, p=0.776\right)$, although frequency on days of reported use between groups was significant $\left(\chi^{2}=9.14\right.$, $p=0.010$ ) with $74.6 \%$ of recreational users reporting using at least twice per day versus $52.9 \%$ of therapeutic users reporting using at least twice. Table 2 provides additional information related to differences in use characteristics between the two marijuana use groups.

The most prevalent reported ROAs were joints $(82.7 \%)$, followed by blunts (75.6\%), pipes (54.5\%), edibles $(20.7 \%)$, and vaporizing devices (19.2\%). Recreational users were more likely than therapeutic users to smoke joints $\left(\chi^{2}=5.96\right.$, $p=0.015)$ and consume edibles $\left(\chi^{2}=7.84, p=0.005\right)$.

\section{Demographics, substance use, and ART adherence among therapeutic users, recreational users, and nonusers}

The 45-54 years age group had the highest prevalence of therapeutic use and recreational use $\left(\chi^{2}=17.95, p=0.006\right)$. Males were more likely to report recreational use while therapeutic use was more prevalent among females $\left(\chi^{2}=9.20\right.$, $p=0.010$ ). Homeless individuals were most likely to report recreational use $\left(\chi^{2}=9.03, p=0.011\right)$. There were no significant differences in the type of marijuana use related to education, race, or marital status.

Regarding substance misuse and type of marijuana use, hazardous drinkers were most likely to engage in recreational use, while those reporting less than hazardous levels of alcohol consumption were most likely to report therapeutic marijuana use $\left(\chi^{2}=18.28, p=0.001\right)$. Among individuals using other illicit substances, current drug users were most likely to report

Table I Prevalence of reported recreational and therapeutic reasons for marijuana use $(\mathrm{N}=703)$

\begin{tabular}{llll}
\hline $\begin{array}{l}\text { Recreational or } \\
\text { therapeutic use }\end{array}$ & Reason & Frequency & Percentage \\
\hline Recreational use & To get high/stoned & 162 & 23.0 \\
& To improve sexual performance & 76 & 10.8 \\
& To fit into social situations & 77 & 1.0 \\
Therapeutic use & To improve appetite/gain weight & 150 & 21.3 \\
& To induce sleep & 157 & 22.3 \\
& To relieve nausea/vomiting & 105 & 14.9 \\
& To relieve pain & 156 & 22.2 \\
\hline
\end{tabular}

Note: Participants could select more than one option. 
Table 2 Frequency, quantity, and duration of use among marijuana users $(n=234)$

\begin{tabular}{|c|c|c|c|c|c|c|}
\hline Marijuana use variables & Category & $\begin{array}{l}\text { Therapeutic users } \\
(n=51)\end{array}$ & $\begin{array}{l}\text { Recreational users } \\
(n=183)\end{array}$ & $\begin{array}{l}\text { Total } \\
(n=234)\end{array}$ & $\begin{array}{l}\text { Chi-square } \\
\text { value }\end{array}$ & $p$-value \\
\hline \multirow[t]{4}{*}{ Frequency } & Daily & $14(27.5)$ & $64(35.0)$ & $78(33.3)$ & 1.10 & 0.776 \\
\hline & Weekly & $13(25.5)$ & $43(23.5)$ & $56(23.9)$ & & \\
\hline & Monthly & $10(19.6)$ & $34(18.5)$ & $44(18.9)$ & & \\
\hline & $<$ monthly & $14(27.5)$ & $42(23.0)$ & $56(23.9)$ & & \\
\hline \multirow[t]{3}{*}{ Frequency of use on days of use } & $4+$ & $7(13.7)$ & $43(23.8)$ & $50(21.6)$ & 9.14 & 0.010 \\
\hline & $2-3$ & $20(39.2)$ & $92(50.8)$ & $112(48.3)$ & & \\
\hline & I & $24(47.0)$ & $46(25.4)$ & $70(30.2)$ & & \\
\hline \multirow[t]{5}{*}{ Duration of at least weekly use } & $>15$ years & $15(29.4)$ & $65(36.1)$ & $80(34.6)$ & 2.63 & 0.620 \\
\hline & $11-15$ years & $4(7.8)$ & $22(12.2)$ & $26(11.3)$ & & \\
\hline & $6-10$ years & $9(17.6)$ & $30(16.7)$ & $39(16.9)$ & & \\
\hline & $1-5$ years & II (2I.6) & $26(14.4)$ & $37(20.6)$ & & \\
\hline & $<$ I year & $12(23.5)$ & $37(20.6)$ & $49(2 \mid .2)$ & & \\
\hline
\end{tabular}

Notes: " $n$ " may vary slightly according to missing data. Bold values indicate significance at $p<0.05$.

recreational marijuana use $\left(\chi^{2}=15.01, p=0.001\right)$ compared with therapeutic users and nonusers. There were no significant differences between groups regarding symptoms of anxiety or depression. Recreational marijuana users showed significantly less optimal ART adherence compared to therapeutic marijuana users and nonusers $\left(\chi^{2}=14.28, p=0.001\right)$. Table 3 provides information related to differences in study variables between recreational and therapeutic users, and nonusers.

\section{Predictors of ART adherence}

Unadjusted results show that therapeutic use to manage HIV-associated medical symptoms was not significantly associated with suboptimal ART adherence (odds ratio $[\mathrm{OR}]=1.44,95 \% \mathrm{CI}=0.78-2.66, p=0.234)$, while recreational use $(\mathrm{OR}=1.97,95 \% \mathrm{CI}=1.37-2.82, p<0.0001)$ was associated with greater odds of suboptimal ART adherence in comparison with nonuse. These associations remained consistent in adjusted models, as therapeutic use of marijuana was not associated with ART adherence $(\mathrm{AOR}=1.19$, $95 \% \mathrm{CI}=0.60-2.38, p=0.602)$ while recreational marijuana users showed significantly greater odds of suboptimal ART adherence as compared with nonusers (AOR $=1.80,95 \%$ $\mathrm{CI}=1.18-2.72, p=0.005)$. Table 4 summarizes other factors associated with suboptimal adherence.

\section{Discussion}

Of the 30 states with legislation legalizing marijuana, nine states and the District of Colombia have legalized marijuana for recreational use. Our results suggest differences in adherence behavior between individuals who report using marijuana recreationally versus those who report using to manage HIV-associated symptoms. Specifically, we found recreational use to be associated with lower ART adherence, supporting our hypothesis. There were no significant differences between recreational and therapeutic marijuana users regarding frequency of marijuana use. However, there was a significant difference in the average number of times marijuana was used on a typical day when participants reported use, such that nearly $75 \%$ of recreational users reported using marijuana at least twice on days of reported use, while only $53 \%$ of therapeutic users reported using at least twice. Thus, recreational users may have been more likely to evidence suboptimal adherence not as a result of the number of days they used, but rather the number of times used on those days.

The mechanism behind lower ART adherence among recreational marijuana users may also be related to the use of other substances. The literature supports an association between non-marijuana substance use and suboptimal ART adherence. ${ }^{8,42-44}$ Bivariate analyses revealed a statistically significant negative association between hazardous drinking and other illicit drug use and ART adherence in our sample, and recreational marijuana users in our sample showed a higher prevalence of use of such substances compared to therapeutic users. To this point, Lake et al recently found that marijuana use was associated with suboptimal ART adherence only during reported periods of binge alcohol use. ${ }^{45}$ As such, the higher prevalence of hazardous drinking among recreational marijuana users compared with therapeutic users and nonusers may explain the significant association between recreational marijuana use and suboptimal ART adherence. Another explanation for our findings may be that those who use primarily for therapeutic reasons may be more generally focused on their health and thus more adherent to ART. In line with previous findings, De Jong et al found that adults living with HIV with moderate to 
Table 3 Demographics, substance use, mental health, and health status differences among recreational and therapeutic marijuana users and nonusers $(\mathrm{N}=703)$

\begin{tabular}{|c|c|c|c|c|c|c|c|}
\hline Variables & Category & $\begin{array}{l}\text { Nonusers } \\
(n=469)\end{array}$ & $\begin{array}{l}\text { Therapeutic } \\
\text { users }(n=5 I)\end{array}$ & $\begin{array}{l}\text { Recreational } \\
\text { users }(n=\mid 83)\end{array}$ & $\begin{array}{l}\text { Total } \\
(\mathrm{N}=703)\end{array}$ & $\begin{array}{l}\text { Chi-square } \\
\text { value }\end{array}$ & $p$-value \\
\hline \multicolumn{8}{|l|}{ Demographics } \\
\hline \multirow[t]{4}{*}{ Age (years) } & $18-34$ & $59(12.9)$ & $10(19.6)$ & $43(23.4)$ & $112(16.2)$ & 17.95 & 0.006 \\
\hline & $35-44$ & $80(17.5)$ & II (2I.6) & $33(18.0)$ & $124(17.9)$ & & \\
\hline & $45-54$ & I84 (40.3) & $22(43.1)$ & $73(40.0)$ & $279(40.4)$ & & \\
\hline & $\geq 55$ & $134(29.3)$ & $8(15.7)$ & $34(18.6)$ & $176(25.5)$ & & \\
\hline \multirow[t]{2}{*}{ Sex } & Male & 301 (65.9) & $32(62.8)$ & $142(77.6)$ & $475(68.7)$ & 9.29 & 0.010 \\
\hline & Female & $156(34.1)$ & $19(37.2)$ & $4 I(22.4)$ & $216(31.3)$ & & \\
\hline \multirow[t]{4}{*}{ Race } & Hispanic & $102(22.3)$ & $10(19.6)$ & $29(15.8)$ & I4I (20.4) & 9.12 & 0.167 \\
\hline & Not Hispanic, White & $99(21.7)$ & $9(17.6)$ & $47(25.7)$ & $155(22.4)$ & & \\
\hline & Not Hispanic, Black & $242(53.0)$ & $32(62.8)$ & $97(53.0)$ & $37 \mid(53.7)$ & & \\
\hline & Not Hispanic, others & $14(3.0)$ & $0(0.0)$ & $10(5.5)$ & $24(3.5)$ & & \\
\hline \multirow[t]{3}{*}{ Education } & $<$ high school & $142(3 \mid .2)$ & $18(35.3)$ & $60(32.8)$ & $220(31.9)$ & 6.29 & 0.178 \\
\hline & High school diploma or equivalent & $127(27.9)$ & $19(37.3)$ & $62(33.9)$ & $208(30.2)$ & & \\
\hline & $>$ high school & $186(40.9)$ & $14(27.4)$ & $61(33.3)$ & $26 I(37.9)$ & & \\
\hline \multirow[t]{2}{*}{ Homelessness } & No & $391(86.5)$ & $46(90.1)$ & $139(76.0)$ & $576(84.5)$ & 9.03 & 0.011 \\
\hline & Yes & $61(13.5)$ & $5(9.9)$ & $40(24.0)$ & $106(15.5)$ & & \\
\hline \multirow[t]{2}{*}{ Marital status } & Married/living with a long-term partner & $81(17.8)$ & $14(27.4)$ & $36(19.6)$ & $|3|(19.0)$ & 2.84 & 0.241 \\
\hline & Divorced/widowed/separated/single & $374(82.2)$ & $37(72.6)$ & $147(80.4)$ & $558(81.0)$ & & \\
\hline \multicolumn{8}{|l|}{ Substance use } \\
\hline \multirow[t]{2}{*}{ Other drug use } & No & $291(67.8)$ & $32(66.7)$ & $93(51.3)$ & $416(63.2)$ & $|5.0|$ & 0.001 \\
\hline & Yes & $138(32.2)$ & $16(33.3)$ & $88(48.7)$ & $242(36.8)$ & & \\
\hline \multirow[t]{2}{*}{ Cigarettes } & No & $249(56.7)$ & $15(30.0)$ & $62(34.9)$ & $326(48.9)$ & 31.99 & $<0.001$ \\
\hline & Yes & $190(43.3)$ & $35(70.0)$ & $116(65.1)$ & $34 I(5 I . I)$ & & \\
\hline \multirow[t]{2}{*}{ Hazardous drinking } & No & $292(67.6)$ & $38(76.0)$ & $87(50.9)$ & 417 (63.9) & 18.28 & 0.001 \\
\hline & Yes & $140(32.4)$ & $12(24.0)$ & $84(49.1)$ & $236(36.1)$ & & \\
\hline \multicolumn{8}{|l|}{ Mental health } \\
\hline \multirow[t]{2}{*}{ Depression } & $<10$, no depression & $312(69.2)$ & $31(62.0)$ & $122(67.8)$ & $465(68.2)$ & 1.10 & 0.577 \\
\hline & $\geq 10$, current depression & $139(30.8)$ & $19(38.0)$ & $58(32.2)$ & $216(31.8)$ & & \\
\hline \multirow[t]{2}{*}{ Anxiety } & $<10$, no, mild anxiety & $313(70.3)$ & $33(66.0)$ & $120(68.9)$ & $466(69.7)$ & 0.453 & 0.797 \\
\hline & $\geq 10$, moderate or severe anxiety & $132(29.7)$ & $17(34.0)$ & $54(31.1)$ & $203(30.3)$ & & \\
\hline \multirow[t]{2}{*}{ ART adherence } & $<95 \%$ & $125(27.3)$ & $18(35.3)$ & $78(42.6)$ & $221(32.0)$ & 14.28 & 0.001 \\
\hline & $\geq 95 \%$ & $332(72.7)$ & $33(64.7)$ & $105(57.4)$ & $470(68.0)$ & & \\
\hline
\end{tabular}

Notes: "n" may vary slightly according to missing data. Bold values indicate significance at $p<0.05$.

Abbreviation: ART, antiretroviral therapy.

severe nausea who smoked marijuana showed improved ART adherence. ${ }^{5}$

Reports of marijuana use to manage anxiety, depression, or stress were made by $79.4 \%$ of marijuana users, while $64.0 \%$ reported use to improve sleep and manage pain. Although previous evidence indicates that marijuana may be useful in treating such symptoms, use can also escalate toward dependence, as marijuana use disorder is prevalent in $~ 30 \%$ of marijuana users. ${ }^{46}$ Previous research has shown cognitive behavioral therapies (CBTs) to be effective for treating chronic pain and insomnia, as well as psychological and substance use disorders associated with these conditions. ${ }^{47-49}$ Therefore, CBTs may offer an effective treatment for medical comorbidities commonly associated with HIV. Identifying psychological distress and providing appropriate referrals for intervention may improve the quality of life of PLWH, especially given findings from previous studies of improved ART adherence with psychotherapeutic interventions. ${ }^{50-53}$

\section{Limitations and strengths}

Our study has limitations and strengths of note. Although the majority of marijuana users reported using for both therapeutic and recreational reasons, only 18 participants reported recreational use exclusively, leading authors to classify recreational marijuana users as those who reported both therapeutic use and recreational use. In addition, individuals reporting using marijuana to "fit into a social situation" were categorized as recreational users, based on Schauer et al definition of recreational use..$^{34}$ Although this statement may have therapeutic connotations (ie, symptoms 
Table 4 Logistic regression examining the association between type of marijuana use and ART adherence $(<95 \%)(\mathrm{N}=703)$

\begin{tabular}{|c|c|c|c|c|}
\hline Variables & Unadjusted OR $(\mathrm{Cl})^{\mathrm{a}}$ & $p$-value & Adjusted OR (Cl) & $p$-value \\
\hline \multicolumn{5}{|l|}{ Marijuana use } \\
\hline No marijuana use & Referent & & Referent & \\
\hline Therapeutic use & I.44 (0.78-2.66) & 0.234 & $1.19(0.60-2.38)$ & 0.602 \\
\hline Recreational use & $1.97(1.37-2.82)$ & $<0.000$ I & $1.80(1.18-2.72)$ & 0.005 \\
\hline \multicolumn{5}{|l|}{ Sex } \\
\hline Male & Referent & & Referent & \\
\hline Female & $1.19(0.85-1.67)$ & 0.301 & $1.39(0.93-2.07)$ & 0.104 \\
\hline \multicolumn{5}{|l|}{ Age (years) } \\
\hline $18-34$ & Referent & & Referent & \\
\hline $35-44$ & $\mathrm{I} .30(0.77-2.2 \mathrm{I})$ & 0.317 & $\mathrm{I} .56(0.87-2.8 \mathrm{I})$ & 0.120 \\
\hline $45-54$ & $0.86(0.54-1.38)$ & 0.549 & $0.97(0.57-1.63)$ & 0.965 \\
\hline$\geq 55$ & $0.81(0.49-1.35)$ & 0.439 & $0.98(0.54-1.77)$ & 0.961 \\
\hline \multicolumn{5}{|l|}{ Race } \\
\hline Hispanic & Referent & & Referent & \\
\hline Not Hispanic, White & $0.70(0.42-1.16)$ & 0.169 & $0.52(0.30-0.93)$ & 0.028 \\
\hline Not Hispanic, Black & $1.23(0.81-1.86)$ & 0.316 & $0.83(0.5 \mathrm{I}-1.33)$ & $0.44 I$ \\
\hline Not Hispanic, others & $0.72(0.27-1.95)$ & 0.526 & $0.57(0.19-1.65)$ & 0.306 \\
\hline \multicolumn{5}{|l|}{ Homelessness } \\
\hline No & Referent & & Referent & \\
\hline Yes & $2.21(1.46-3.36)$ & $<0.0001$ & $1.76(1.09-2.84)$ & 0.020 \\
\hline \multicolumn{5}{|l|}{ Cigarette smoking } \\
\hline No & Referent & & Referent & \\
\hline Yes & $1.84(1.33-2.56)$ & $<0.0001$ & $1.30(0.88-1.91)$ & 0.175 \\
\hline \multicolumn{5}{|l|}{ Hazardous drinking } \\
\hline No & Referent & & Referent & \\
\hline Yes & $1.84(1.32-2.57)$ & $<0.000$ I & $1.38(0.94-2.03)$ & 0.100 \\
\hline \multicolumn{5}{|l|}{ Other drug use } \\
\hline No & Referent & & Referent & \\
\hline Yes & $1.59(1.13-2.22)$ & 0.006 & $1.27(0.86-1.88)$ & 0.213 \\
\hline
\end{tabular}

Notes: annadjusted odds ratio; badjusted odds ratio. Bold values indicate significance at $p<0.05$.

Abbreviations: ART, antiretroviral therapy; OR, odds ratio.

related to anxiety), only three participants reported marijuana use exclusively for this purpose, and thus, categorizing these participants as therapeutic users as opposed to recreational users would likely not significantly affect our results. In addition, our study used a cross-sectional design, thus we cannot determine the temporality of the observed associations. Furthermore, it is possible that financial compensation could have introduced bias such as social desirability in responding. However, previous research studies suggest that compensation is critical for participation, particularly for vulnerable populations, and further that payment does not encourage drug use or additional risk-taking behaviors. ${ }^{54,55}$ Despite these limitations, this study delineated differences between recreational users and therapeutic users of marijuana while controlling for significant confounding variables. Our sample comprised high levels of racial and ethnic diversity; therefore, we believe our findings constitute a substantial and relevant contribution to the literature regarding the influence of different reasons for use and ART adherence.

\section{Future directions}

Future studies should examine the association between biologically confirmed (ie, urine toxicology assays for tetrahydrocannabinol [THC] metabolites) marijuana use and viral suppression as well as examine the association between physician prescribed marijuana with ART adherence and viral suppression. Studies examining the influence of marijuana use frequency on days of use may elucidate potential reasons for lower ART adherence among recreational marijuana users. Larger samples would also help elucidate group differences between participants reporting exclusively therapeutic/medicinal, recreational, or combined marijuana use. In addition, investigations examining dronabinol versus whole-leaf marijuana as well as other forms of marijuana consumption (eg, edibles), and ART adherence would also be helpful in determining the most effective clinical interventions for PLWH. Qualitative interviews involving marijuana users would advance our understanding of the association of marijuana use and ART adherence, complementing 
quantitative data and allowing users to provide perspective for their own experiences.

\section{Conclusion}

To our knowledge, this is the first study assessing the association between motive for use of marijuana and ART adherence. Recreational marijuana users showed significantly greater odds of suboptimal ART adherence as compared with nonusers, while therapeutic marijuana use was not associated with ART adherence in the Florida Cohort sample. Previous studies suggest that the prevalence of marijuana use among PLWH is high and that motives for use differ (ie, some consume marijuana for recreational reasons while others consume for therapeutic reasons that help manage HIVassociated medical symptoms). ${ }^{12,17,19}$ Our findings contribute to the literature by examining relevant distinctions among marijuana users that impact ART adherence by underscoring the importance of discerning motivation for marijuana use when considering the effect of marijuana on ART adherence among PLWH. Our findings also speak to a potential need to consider recreational versus therapeutic/medical marijuana users as two separate groups, rather than one homogenous group of marijuana users. Given the differences in adherence observed in this study based on motive for use, classification of marijuana users into distinct groups may prove beneficial for future research to gain a more nuanced understanding of the health-related consequences of marijuana use among PLWH.

Medical marijuana is currently legal in 30 states and the District of Columbia. In these territories, HIV/AIDS is recognized as one of the most common ailments for which physicians prescribe medical marijuana. ${ }^{56}$ Moreover, legalization of recreational marijuana use continues to expand in the United States and Canada. As these trends continue, studies examining the health effects of medical and recreational marijuana use will be helpful in informing PLWH and those responsible for their care about potential health effects of marijuana use.

\section{Acknowledgments}

We appreciate the contributions of the research staff and the participants who were involved in the Florida Cohort study.

This study was funded by the NIAAA (grant number U24AA022002); National Institute on Drug Abuse (NIDA; grant number 1K23DA039769-01); and NIDA UF Substance Abuse Training Center (grant number T32DA035167).

\section{Disclosure}

The authors report no conflicts of interest in this work.

\section{References}

1. Antiretroviral Therapy Cohort Collaboration. Life expectancy of individuals on combination antiretroviral therapy in high-income countries: a collaborative analysis of 14 cohort studies. Lancet. 2008;372(9635): 293-299.

2. May MT, Gompels M, Delpech V, et al. Impact on life expectancy of HIV-1 positive individuals of CD4+ cell count and viral load response to antiretroviral therapy. AIDS. 2014;28(8):1193.

3. Price AJ, Glynn J, Chihana M, et al. Sustained 10-year gain in adult life expectancy following antiretroviral therapy roll-out in rural Malawi: July 2005 to June 2014. Int J Epidemiol. 2016;46(2):479-491.

4. Cohen MS, Gay CL. Treatment to prevent transmission of HIV-1. Clin Infect Dis. 2010;50(Suppl 3):S85-S95.

5. de Jong BC, Prentiss D, McFarland W, Machekano R, Israelski DM. Marijuana use and its association with adherence to antiretroviral therapy among HIV-infected persons with moderate to severe nausea. J Acquir Immune Defic Syndr. 2005;38(1):43-46.

6. Simoni JM, Huh D, Wilson IB, et al. Racial/ethnic disparities in ART adherence in the United States: findings from the MACH14 study. J Acquir Immune Defic Syndr. 2012;60(5):466.

7. Uthman OA, Magidson JF, Safren SA, Nachega JB. Depression and adherence to antiretroviral therapy in low-, middle- and high-income countries: a systematic review and meta-analysis. Curr HIV/AIDS Rep. 2014;11(3): 291-307.

8. Zhang Y, Wilson TE, Adedimeji A, et al. The impact of substance use on adherence to antiretroviral therapy among HIV-infected women in the United States. AIDS Behav. 2018;22(3):896-908.

9. Abrams DI, Hilton JF, Leiser RJ, et al. Short-term effects of cannabinoids in patients with HIV-1 infection: a randomized, placebo-controlled clinical trial. Ann Intern Med. 2003;139(4):258-266.

10. Abrams DI, Jay CA, Shade SB, et al. Marijuana in painful HIVassociated sensory neuropathy: a randomized placebo-controlled trial. Neurology. 2007;68(7):515-521.

11. Ellis RJ, Toperoff W, Vaida F, et al. Smoked medicinal marijuana for neuropathic pain in HIV: a randomized, crossover clinical trial. Neuropsychopharmacology. 2009;34(3):672-680.

12. Woolridge E, Barton S, Samuel J, Osorio J, Dougherty A, Holdcroft A. Marijuana use in HIV for pain and other medical symptoms. $J$ Pain Symptom Manage. 2005;29(4):358-367.

13. Gamarel KE, Brown L, Kahler CW, Fernandez MI, Bruce D, Nichols S; Adolescent Medicine Trials Network for HIV/AIDS Intervention. Prevalence and correlates of substance use among youth living with HIV in clinical settings. Drug Alcohol Depend. 2016;169: 11-18.

14. Fogarty A, Rawstorne P, Prestage G, Crawford J, Grierson J, Kippax S. Marijuana as therapy for people living with HIV/AIDS: social and health aspects. AIDS Care. 2007;19(2):295-301.

15. Harris GE, Dupuis L, Mugford GJ, et al. Patterns and correlates of marijuana use among individuals with HIV/AIDS in Maritime Canada. Can J Infect Dis Med Microbiol. 2014;25(1):e1-e7.

16. Mimiaga MJ, Reisner SL, Grasso C, et al. Substance use among HIVinfected patients engaged in primary care in the United States: findings from the Centers for AIDS Research Network of Integrated Clinical Systems cohort. Am J Public Health. 2013;103(8):1457-1467.

17. Prentiss D, Power R, Balmas G, Tzuang G, Israelski DM. Patterns of marijuana use among patients with HIV/AIDS followed in a public health care setting. J Acquir Immune Defic Syndr. 2004;35(1): 38-45

18. Haney M, Gunderson EW, Rabkin J, et al. Dronabinol and marijuana in HIV-positive marijuana smokers: caloric intake, mood, and sleep. J Acquir Immune Defic Syndr. 2007;45(5):545-554. 
19. D'Souza G, Matson P, Grady CD, et al. Medicinal and recreational marijuana use among HIV-infected women in the Women's Interagency HIV Cohort (WIHS), 1994-2010. J Acquir Immune Defic Syndr. 2012;61(5): 618-626.

20. Volkow ND, Baler RD, Compton WM, Weiss SR. Adverse health effects of marijuana use. N Engl J Med. 2014;370(23):2219-2227.

21. Solowij N, Stephens RS, Roffman RA, et al. Cognitive functioning of long-term heavy marijuana users seeking treatment. JAMA. 2002;287(9): 1123-1131.

22. Cristiani SA, Pukay-Martin ND, Bornstein RA. Marijuana use and cognitive function in HIV-infected people. J Neuropsychiatry Clin Neurosci. 2004;16(3):330-335.

23. National Academies of Sciences, Engineering, and Medicine. The health effects of marijuana and cannabinoids: the current state of evidence and recommendations for research. National Academies Press; 2017.

24. Slawson G, Milloy MJ, Balneaves L, et al. High-intensity marijuana use and adherence to antiretroviral therapy among people who use illicit drugs in a Canadian setting. AIDS Behav. 2015;19(1):120-127.

25. Bonn-Miller MO, Oser ML, Bucossi MM, Trafton JA. Marijuana use and HIV antiretroviral therapy adherence and HIV-related symptoms. J Behav Med. 2014;37(1):1-10.

26. Corless IB, Lindgren T, Holzemer W, et al. Marijuana effectiveness as an HIV self-care strategy. Clin Nurs Res. 2009;18(2):172-193.

27. Lancaster KE, Lungu T, Mmodzi P, et al. The association between substance use and sub-optimal HIV treatment engagement among HIVinfected female sex workers in Lilongwe, Malawi. AIDS Care. 2017; 29(2):197-203.

28. Wilson KJ, Doxanakis A, Fairley CK. Predictors for non-adherence to antiretroviral therapy. Sex Health. 2005;1(4):251-257.

29. Centers for Disease Control and Prevention. Diagnoses of HIV infection in the United States and dependent areas, 2015. HIV Surveill Rep. 2016;27:1-114.

30. Kelso-Chichetto NE, Okafor CN, Harman JS, Canidate SS, Cook CL, Cook RL. Complementary and alternative medicine use for HIV management in the state of Florida: medical monitoring project. J Altern Complement Med. 2016;22(11):880-886.

31. Wilson IB, Lee Y, Michaud J, Fowler FJ, Rogers WH. Validation of a new three-item self-report measure for medication adherence. AIDS Behav. 2016;20(11):2700-2708

32. Wood E, Hogg RS, Yip B, Harrigan PR, O'shaughnessy MV, Montaner JS. Is there a baseline CD4 cell count that precludes a survival response to modern antiretroviral therapy? AIDS. 2003;17(5): 711-720.

33. Wood E, Montaner JS, Yip B, et al. Adherence and plasma HIV RNA responses to highly active antiretroviral therapy among HIV-1 infected injection drug users. Can Med Assoc J. 2003;169(7):656-661.

34. Schauer GL, King BA, Bunnell RE, Promoff G, McAfee TA. Toking, vaping, and eating for health or fun: marijuana use patterns in adults, US, 2014. Am J Prevent Med. 2016;50(1):1-8.

35. Braithwaite RS, Conigliaro J, Roberts MS, et al. Estimating the impact of alcohol consumption on survival for HIV+ individuals. AIDS Care. 2007;19(4):459-466.

36. Vagenas P, Azar MM, Copenhaver MM, Springer SA, Molina PE, Altice FL. The impact of alcohol use and related disorders on the HIV continuum of care: a systematic review. Curr HIV/AIDS Rep. 2015;12(4): 421-436.

37. Kroenke K, Strine TW, Spitzer RL, Williams JB, Berry JT, Mokdad AH. The PHQ-8 as a measure of current depression in the general population. J Affect Disord. 2009;114(1):163-173.

38. Do AN, Rosenberg ES, Sullivan PS, et al. Excess burden of depression among HIV-infected persons receiving medical care in the United States: data from the medical monitoring project and the behavioral risk factor surveillance system. PLoS One. 2014;9(3):e92842.
39. Shacham E, Morgan JC, Önen NF, Taniguchi T, Overton ET. Screening anxiety in the HIV clinic. AIDS Behav. 2012;16(8):2407-2413.

40. Dear BF, Titov N, Sunderland M, McMillan D, Anderson T, Lorian C, Robinson E. Psychometric comparison of the generalized anxiety disorder scale-7 and the Penn State Worry Questionnaire for measuring response during treatment of generalised anxiety disorder. Cogn Behav Ther. 2011;40(3):216-227.

41. Nie NH, Bent DH, Hull CH. SPSS: Statistical Package for the Social Sciences (No. HA29 S6). New York: McGraw-Hill; 1970.

42. Arnsten JH, Demas PA, Grant RW, et al. Impact of active drug use on antiretroviral therapy adherence and viral suppression in HIV-infected drug users. J Gen Intern Med. 2002;17(5):377-381.

43. Baum MK, Rafie C, Lai S, Sales S, Page JB, Campa A. Alcohol use accelerates HIV disease progression. AIDS Res Hum Retroviruses. 2010;26(5):511-518.

44. Hinkin CH, Hardy DJ, Mason KI, et al. Medication adherence in HIVinfected adults: effect of patient age, cognitive status, and substance abuse. AIDS. 2004;18(Suppl 1):S19

45. Lake S, Kerr T, Capler R, Shoveller J, Montaner J, Milloy MJ. Highintensity marijuana use and HIV clinical outcomes among HIV-positive people who use illicit drugs in Vancouver, Canada. Int J Drug Policy. 2017;42:63-70.

46. Hasin DS, Saha TD, Kerridge BT, et al. Prevalence of marijuana use disorders in the United States between 2001-2002 and 2012-2013. JAMA Psychiatry. 2015;72(12):1235-1242.

47. Hoffman BM, Papas RK, Chatkoff DK, Kerns RD. Meta-analysis of psychological interventions for chronic low back pain. Health Psychol. 2007;26(1):1-9.

48. Jhanjee S. Evidence based psychosocial interventions in substance use. Indian J Psychol Med. 2014;36(2):112-118.

49. Mitchell MD, Gehrman P, Perlis M, Umscheid CA. Comparative effectiveness of cognitive behavioral therapy for insomnia: a systematic review. BMC Fam Pract. 2012;13(1):40.

50. Diiorio C, McCarty F, Resnicow K, et al. Using motivational interviewing to promote adherence to antiretroviral medications: a randomized controlled study. AIDS Care. 2008;20(3):273-283.

51. Fisher JD, Fisher WA, Amico KR, Harman JJ. An information-motivation-behavioral skills model of adherence to antiretroviral therapy. Health Psychol. 2006;25(4):462.

52. Kalichman SC, Cherry J, Cain D. Nurse-delivered antiretroviral treatment adherence intervention for people with low literacy skills and living with HIV/AIDS. J Assoc Nurs AIDS Care. 2005;16(5):3-15.

53. Simoni JM, Wiebe JS, Sauceda JA, et al. A preliminary RCT of CBT-AD for adherence and depression among HIV-positive Latinos on the US-Mexico border: the Nuevo Dia study. AIDS Behav. 2013;17(8): 2816-2829.

54. Slomka J, McCurdy S, Ratliff EA, Timpson S, Williams ML. Perceptions of financial payment for research participation among AfricanAmerican drug users in HIV Studies. J Gen Intern Med. 2007;22(10): 1403-1409.

55. Collins AB, Strike C, Guta A, et al. We're giving you something so we get something in return": perspectives on research participation and compensation among people living with HIV who use drugs. Int J Drug Policy. 2017;39:92-98.

56. Belendiuk KA, Baldini LL, Bonn-Miller MO. Narrative review of the safety and efficacy of marijuana for the treatment of commonly stateapproved medical and psychiatric disorders. Addict Sci Clin Pract. $2015 ; 10(1): 10$ 


\section{Publish your work in this journal}

Patient Preference and Adherence is an international, peer-reviewed, open access journal that focuses on the growing importance of patient preference and adherence throughout the therapeutic continuum. Patient satisfaction, acceptability, quality of life, compliance, persistence and their role in developing new therapeutic modalities and compounds to optimize

clinical outcomes for existing disease states are major areas of interest for the journal. This journal has been accepted for indexing on PubMed Central. The manuscript management system is completely online and includes a very quick and fair peer-review system, which is all easy to use. Visit http://www. dovepress.com/testimonials.php to read real quotes from published authors.

Submit your manuscript here: http://www.dovepress.com/patient-preference-and-adherence-journal 